\title{
Metabolism of six CYP probe substrates in fetal hepatocytes
}

\author{
Abdul Naveed Shaik*1,2 ${ }^{1,}$ Sandeep Kumar Vishwakarma ${ }^{1}$ and Aleem Ahmed Khan ${ }^{1}$ \\ ${ }^{1}$ Center for Liver Research and Diagnostics, Owaisi Research Center, Deccan College of Medical Sciences, Hyderabad, \\ TS, India \\ ${ }^{2}$ Department of Pharmaceutical Sciences, MCPHS University, Boston MA, USA \\ *Corresponding Author. E-mail: naveedshaik@gmail.com; Tel.: +1-407-303-7003; Fax: +1-407-303-7030 \\ Received: August 12, 2016; Revised: October 02, 2016; Published: June 29, 2016
}

\begin{abstract}
Cytochrome P-450 (CYP) are the most common drug metabolizing enzymes and are abundantly expressed in liver apart from kidney, lungs, intestine, brain etc. Their expression levels change with physiological conditions and disease states. The expression of these CYPs is less in human foetus and neonates compared to adults, which results in lower clearance of xenobiotics in infants and neonates compared to adults. Hepatocytes are the cells which are largely used to study these CYPs. We have isolated hepatocytes from aborted foetus to study the metabolism of six probe substrates: phenacetin, diclofenac, $S$-mephenytoin, dextromethorphan, nifedipine and testosterone. The results obtained show the expression of various CYPS (CYP1A2, CYP2C19, CYP2C9, CYP2D6, and CYP3A4) in human foetus and their involvement in metabolism of CYP probe substrates.
\end{abstract}

\section{Keywords}

Fetal metabolism; CYP (Cytochrome-P450); hepatocytes; metabolic stability; HPLC; dextromethorphan; diclofenac; S-mephenytoin; nifedipine; testosterone.

\section{Introduction}

The role of Cytochromes P450 (CYP) mediated metabolism is well appreciated in the drug discovery setup, over the last few decades much emphasis has been laid on how different drugs are handled by the CYPs. CYPs are one of the major source of variability in pharmacokinetics (PK) and pharmacodynamics (PD) of the drugs [1]. The CYPs are widely distributed and expressed in different organs including, liver, intestine, lungs, kidney, placenta, brain etc. The highest expression levels are observed in liver, and the major ones to be expressed in liver are CYPs $3 A 4,2 C 9,2 C 8,2 E 1$, and $1 A 2$ [2]. These five isoforms are responsible for the biotransformation of many of the drugs in market which makes up to $80 \%$ of the total drugs in clinical use. Expression of these CYP enzymes depends on varied factors including sex, age, disease states, etc [3]. The mechanism of these CYP isoforms and their contribution towards drug-drug interactions leading to either changes in label or complete withdrawal from the market has been well understood [4]. Even though thorough investigations of these CYPs including their polymorphism led to relatively safer prescription practices [5], involvement of fetal metabolism still remains highly disparaged [6-9]. Role of CYP enzymes in clearance of drugs from foetus and neonates is explored since early 70's, but the lack of microsomes and hepatocytes of fetal and neonatal origin has greatly limited our understanding of the drug behaviour in 
foetus and neonates. Furthermore, lack of complete knowledge of adverse events related to drugs and scant data of PK parameters during pregnancy leads to either cautious prescription or complete avoidance of many drugs [10-12]. Advances in drug metabolism, drug transport and drug-drug interactions in human foetus will greatly benefit the patients and clinicians alike [13]. Hepatocytes are considered as one of the better in vitro tools to study metabolism [14,15], therefore we explored the metabolic stability of six probe substrates: phenacetin (CYP1A2), diclofenac (CYP2C9), S-mephenytoin (CYP2C19), dextromethorphan (CYP2D6), nifedipine (CYP3A4) and testosterone (CYP3A4) in hepatocytes of fetal origin [16].

\section{Experimental}

\section{Chemicals and Reagents}

Diclofenac, 4-hydroxydiclofenac, dextromethorphan, dextrorphan, phenacetin, paracetamol, Smephenytoin, 4-hydroxymephenytoin, nifedipine, oxidized nifedipine, testosterone, 6 $\beta$ hydroxytestosterone, celecoxib, DMSO (dimethyl sulfoxide), DMEM (Dulbecco's modified eagles medium), PBS (phosphate buffer saline) were obtained from Sigma Aldrich (St. Louis, MO USA). HPLC (high performance liquid chromatography) grade acetonitrile and methanol were obtained from E Merck India Limited (Mumbai, India), and all the other chemicals were used of highest quality available.

\section{Hepatocytes isolation, in vitro culture and characterization}

Human fetal livers were obtained from spontaneous abortions from 10-14 weeks of gestation. All donors of the fetus were thoroughly screened serologically for syphilis, toxoplasmosis, rubella, hepatitis B and C, human immunodeficiency virus 1 , cytomegalovirus, parvovirus, and herpes simplex types 1 and 2 . Liver cells were isolated using two-step collagenase perfusion method as described by Habibullah et al [17]. Briefly, resected liver from the aborted fetuses were collected under sterile conditions within $2 \mathrm{~h}$ of the termination of pregnancy and then cut into thin slice (1-2 mm thickness). Thereafter, each fetal liver was digested with $0.02 \%$ collagenase type IV (SigmaAldrich, St. Louis, USA) containing penicillin G (10 U/ml, streptomycin $10 \mathrm{U} / \mathrm{ml}$, amphoteracin $B(0.025 \mu \mathrm{g} / \mathrm{ml})$ at $37^{\circ} \mathrm{C}$ for $30 \mathrm{~min}$. Single cell suspension of liver was collected by centrifugation at $250 \mathrm{~g}$ and then washed with sterile phosphate buffered saline (PBS pH 7.4). The viability of the cells was measured using trypan blue method. Cells showing more than $80 \%$ viability were used for the metabolism experiments.

\section{Metabolism Studies}

$1 \mathrm{~mL}$ of cell mixture containing 1 million cells per $\mathrm{ml}$ were transferred to a 12 well cell culture plate (costar) and $10 \mu \mathrm{L}$ of test compound (in DMSO water) was added to maintain a final volume of DMSO below $0.2 \% \mathrm{v} / \mathrm{v}$. The incubation plate was then transferred to an incubator set at $37^{\circ} \mathrm{C}$ with a relative humidity of $95 \%$ and $\mathrm{CO}_{2}$ (carbon dioxide) at $5 \%$. The samples were incubated for $2 \mathrm{~h}$ and at the end of $2 \mathrm{~h}$ viability of the cells was checked using an aliquot of $20 \mu \mathrm{L}$ mixture. The incubation was terminated using $4 \mathrm{~mL}$ of acetonitrile containing internal standard celecoxib $(1 \mathrm{mg} / \mathrm{mL})$, vortex mixed for 2 mins and centrifuged at $3000 \mathrm{rpm}$ on a table top centrifuge (Remi Instruments, India). The supernatant was transferred to clean glass tube and the contents were dried under gentle stream of nitrogen using a multivap evaporator set at $40{ }^{\circ} \mathrm{C}$ ( $\mathrm{N}$-evap, Orgiinomation, Berlin, MA, USA). The residue was reconstituted in $200 \mu \mathrm{L}$ of mobile phase (A:B, 1:1) and $100 \mu \mathrm{L}$ of this solution was injected into the HPLC. For $0 \mathrm{~h}$ samples, acetonitrile was added prior to addition of test compound to prevent the reaction followed by the above described sample preparation method.

Each of the test compounds was incubated in triplicates; the area of the drug was divided by the area of 
the internal standard to get the area ratio. The area ratio obtained from $0 \mathrm{~h}$ was considered as $100 \%$ and the area ratio of $2 \mathrm{~h}$ sample was calculated to get the metabolic stability of the test compound. Each of the experiment was conducted at least three times on different days with new fetal hepatocytes.

\section{Instrumentation and Chromatographic Conditions}

HPLC analysis was performed using the previously published method [18]. In brief, HPLC system consisted of a Waters 2695 alliance separation module attached with a Waters 2996 photodiode array (PDA) detector, the instrument was setup to detect a range of 190-400 nm. A C18 Inertsil ODS 3V column (4.6 $\times 250$ mm, $5 \mu \mathrm{m}$, GL Sciences, Inc., Tokyo, Japan) was used for the analysis. A ternary mobile phase gradient system was used consisting of $\mathrm{A}$ ( $0.01 \mathrm{M}$ ammonium acetate, $\mathrm{pH}$ 5.0: acetonitrile; 90:10), $\mathrm{B}(0.01 \mathrm{M}$ ammonium acetate buffer, $\mathrm{pH}$ 5.0: acetonitrile; 5:95) and C- $0.01 \mathrm{mM}$ ammonium acetate buffer, $\mathrm{pH}$ 5.0:methanol; 5:95), the total run time was 40 minutes with gradient flow shown in Table 1, analysis was performed by integrating the peak area of the individual peaks at UV (Ultraviolet) maximum as described by Rao et al [18] and shown in Table 2. Similarly, the peak area counts of internal standard was integrated. The area counts of test compound was divided by the area counts obtained from the internal standard (IS) within the same analytical run to get the area ratios which were used to calculate the \% depletion of the parent compound over a period of $2 \mathrm{~h}$.

\section{Data Analysis}

The data was plotted using Prism software (GraphPad Software Inc., San Diego, CA), all data are presented as the mean of each group \pm S.E.M. (standard error of mean) as indicated in the figure legend. Metabolic stability was calculated using the substrate depletion approach [19], using the equation below [20].

$$
\% \text { Substrate remained in test sample }=\frac{\text { Ratio of substrate in test sample }}{\text { Ratio of substrate in control sample }} * 100
$$

\section{Results and Discussion}

Isolation of hepatocytes from the fetal liver resulted in $80 \%$ viable cell, isolation resulting in less than 80 $\%$ viability, or cells showing visible signs of deterioration were not considered for metabolism experiments. Figure 1 shows microscopic image of the 14 week old healthy hepatocytes. Six of the commonly used probe substrates, phenacetin at a concentration of $100 \mu \mathrm{M}$ as a substrate of CYP1A2 [21], diclofenac at a concentration of $25 \mu \mathrm{M}$ as a substrate of CYP2C9 [22], S-mephenytoin at a concentration of $5 \mu \mathrm{M}$ as a substrate of CYP2C19 [23], dextromethorphan at a concentration of $50 \mu \mathrm{M}$ as a substrate of CYP2D6 [24], nifedipine at a concentration of $5 \mu \mathrm{M}$ as a substrate of CYP3A4 and testosterone at a concentration of 120 $\mu \mathrm{M}$ as a substrate of CYP3A4 [25], were used to evaluate the contribution towards fetal metabolism. These concentrations were chosen based on in-house $K_{\mathrm{m}}$ values generated using liver microsomes and hepatocytes and with reference to the concentrations suggested by the FDA (Food and Drug Administration) guidance for drug interaction studies 2006 [16, 26]. Each of the marker reaction was monitored by comparing the UV peak of metabolite with the analytical standard of each metabolite. The peak area of all the test compound was obtained at lambda max $(\lambda)$ of individual well resolved chromatographic peaks devoid of interference. Table 2 shows UV max and retention time (RT) of all compounds. The following reactions were monitored, phenacetin-O-deethylation as marker reaction of CYP1A2, diclofenac-4-hydroxylation as marker reaction of CYP2C9, S-mephenytoin-4-hydroxylation as marker reaction of CYP2C19, dextromethorphan-O-demethylation as marker reaction of CYP2D6, nifedipine 
oxidation as marker reaction of CYP3A4, and testosterone $6 \beta$-hydroxylation as marker reaction of CYP3A4 to confirm the metabolism by the respective CYPs. Comparison of area ration between $0 \mathrm{~h}$ which was considered as $100 \%$ against $2 \mathrm{~h}$ samples resulted in, $68.2 \pm 8.13 \%, 50.5 \pm 4.29 \%, 79.8 \pm 6.11 \%, 72.2 \pm 6.12$ $\%, 1.32 \pm 0.21 \%$, and $4.26 \pm 0.92 \%$ respectively for phenacetin, diclofenac, S-mephenytoin, dextromethorphan, nifedipine and testosterone respectively. The results are shown as mean of three independent experiments with standard error of mean. Depletion of all the substrates indicates maturation and involvement of CYP1A2, CYP2C9, CYP2C19, CYP2D6, and CYP3A4 in fetal liver. CYP3A4 showed maximum activity, resulting in more than $90 \%$ depletion of both the CYP $3 \mathrm{~A} 4$ substrates nifedipine as well as testosterone, followed by $50 \%$ depletion of diclofenac, $32 \%$ depletion of phenacetin, $28 \%$ depletion of dextromethorphan and $20 \%$ depletion of S-mephenytoin. These results clearly suggest the maturation and involvement of 5 different CYPs in metabolism through human foetus. Due to limitation in availability of fetal tissue other substrates cannot be evaluated. Furthermore, studies to evaluate the kinetic parameters to generate $K_{\mathrm{m}}$ and $V_{\max }$ of each CYP using a probe substrate will be beneficial for the regulatory authorities and clinicians to optimize the dose and prevent drug-drug interactions in pregnant women and neonates.

Table 1. Gradient time program for HPLC with UV detection with ternary gradient mobile phase, method was reproduced from Rao et. al. [18].

\begin{tabular}{|c|c|c|c|c|}
\hline Time, $\mathbf{m i n}$ & Flow, $\mathbf{~} \mathbf{L} / \mathbf{m i n}$ & $\mathbf{\% A}$ & $\mathbf{\% B}$ & \%C \\
\hline 0 & 1 & 100 & 0 & 0 \\
\hline 2 & 1 & 90 & 0 & 10 \\
\hline 9 & 1 & 50 & 20 & 30 \\
\hline 12 & 1 & 50 & 25 & 25 \\
\hline 25 & 1 & 30 & 50 & 20 \\
\hline 28 & 1 & 10 & 85 & 5 \\
\hline 35 & 1 & 10 & 85 & 5 \\
\hline 36 & 1 & 100 & 0 & 0 \\
\hline 40 & 1 & 100 & 0 & 0 \\
\hline
\end{tabular}

A =90:10:: $10 \mu \mathrm{M}$ ammonium acetate: acetonitrile, B =5:95:: $10 \mu \mathrm{M}$ ammonium acetate: acetonitrile, and $\mathrm{C}=5: 95:: 10 \mu \mathrm{M}$ ammonium acetate: methanol

Table 2. Retention times and UV max ( $\lambda$ max) of CYP probe substrates, their metabolites and internal standard.

\begin{tabular}{|c|c|c|}
\hline Compound & UV extracted, $\mathbf{n m}$, & Retention Time, min \\
\hline Phenacetin & 240 & 14.1 \\
\hline Paracetamol & 240 & 7.1 \\
\hline Diclofenac & 280 & 24.9 \\
\hline 4-Hydrxoydiclofenac & 280 & 18.7 \\
\hline S-mephenytoin & 250 & 15.9 \\
\hline 4-Hydroxymephenytoin & 250 & 11.5 \\
\hline Dextromethorphan & 277 & 14.3 \\
\hline Dextrorphan & 277 & 10.3 \\
\hline Nifedipine & 240 & 22.9 \\
\hline Hydroxynifedipine & 240 & 21.2 \\
\hline Testosterone & 240 & 24.4 \\
\hline 63-Hydroxytestosterone & 240 & 15.7 \\
\hline Celecoxib & 250 & 30.1 \\
\hline
\end{tabular}




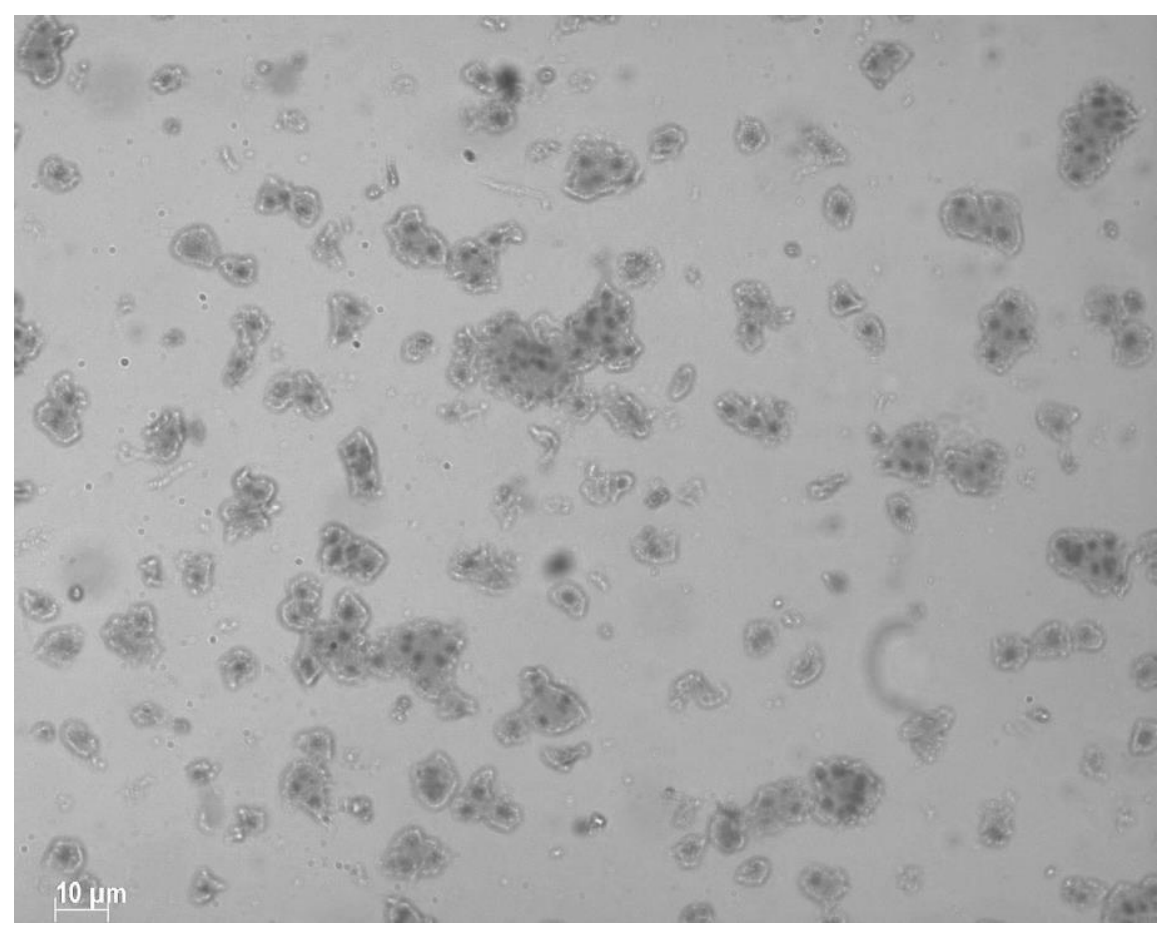

Figure 1. A 10 x microscopic image of the well differentiated hepatocytes of human origin, obtained from 14 week old aborted foetus.

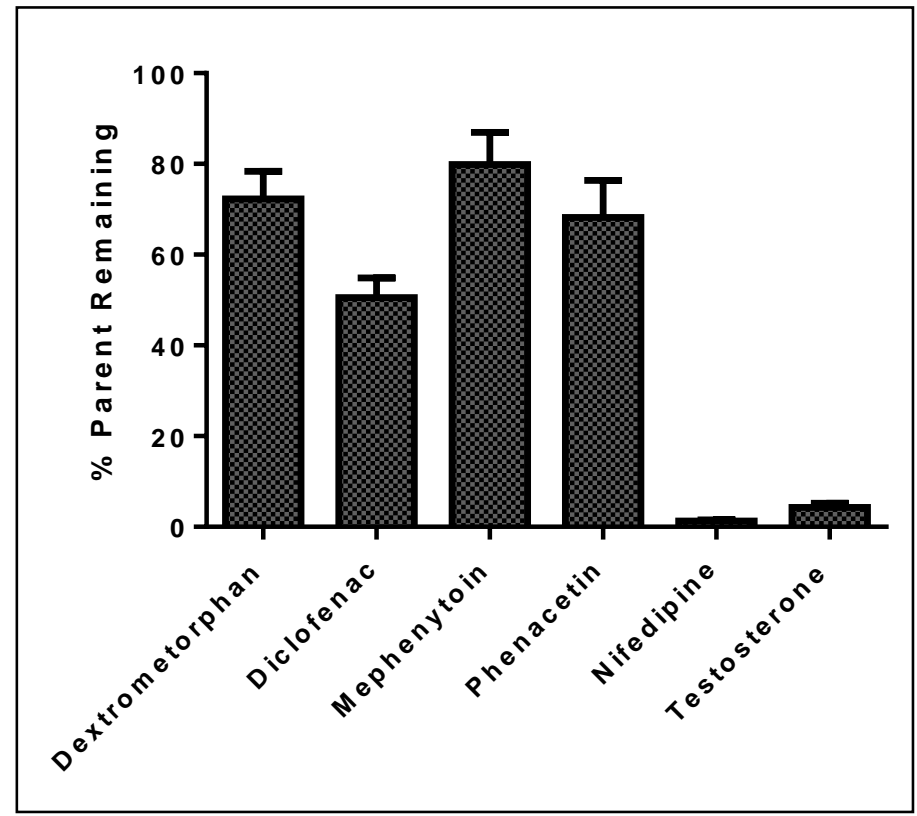

Figure 2. Metabolism of six CYP probe substrates, the bars represent mean of percent remaining of the drug after $2 \mathrm{~h}$ obtained from three independent experiments, the bars represent standard error of mean.

\section{Conclusions}

In conclusion, fetal hepatocytes were successfully isolated from different subjects with viability of greater than $80 \%$ using earlier reported method [17]. These cells were used to perform the metabolism studies of six probe CYP substrates, using parent depletion approach [19, 27]. The results obtained by the commonly used substrate depletion approach $[19,28,29]$ prove differentiation, maturation and involvement of five CYPs (CYP1A2, CYP2C9, CYP2C19, CYP2D6, and CYP3A4) in clearance of phenacetin, diclofenac, S-mepheytoin, dextromethorphan, nifedipine and testosterone from the fetal liver. Furthermore, the percent depletion of testosterone and nifedipine is similar to adults (data not shown) 
suggesting well differentiation of CYP3A4 as compared to other CYPs which resulted in lesser depletion of other substrates. This study was limited by the availability of fetal hepatocytes to calculate the intrinsic clearance $\left(\mathrm{Cl}_{\text {int }}\right)$ commonly used to represent in vitro metabolism [30,31], and determine the mRNA content of CYP450 for head on comparison with adult hepatocytes [32], which will be helpful in designing the doses of different drugs in pregnant women and neonates.

Note: Abdul Naveed Shaik's current affiliation: Center for Pharmacometric and Systems Pharmacology, University of Florida, Orlando FL

\section{References}

[1] U.M. Zanger, M. Schwab, Pharmacology \& therapeutics 138 (2013) 103-141.

[2] J.H. Ansede, D.R. Thakker, Journal of pharmaceutical sciences 93 (2004) 239-255.

[3] J. George, C. Liddle, M. Murray, K. Byth, G.C. Farrell, Biochemical pharmacology 49 (1995) 873-881.

[4] A.S. Kalgutkar, R.S. Obach, T.S. Maurer, Current drug metabolism 8 (2007) 407-447.

[5] S.C. Preissner, M.F. Hoffmann, R. Preissner, M. Dunkel, A. Gewiess, S. Preissner, PloS one 8 (2013) e82562.

[6] B. Krauer, P. Dayer, Clinical pharmacokinetics 21 (1991) 70-80.

[7] M.S. Miller, M.R. Juchau, F.P. Guengerich, D.W. Nebert, J.L. Raucy, Fundamental and applied toxicology : official journal of the Society of Toxicology 34 (1996) 165-175.

[8] M. Garland, K.M. Abildskov, T.W. Kiu, S.S. Daniel, R.I. Stark, Drug metabolism and disposition: the biological fate of chemicals 33 (2005) 68-76.

[9] M.R. Juchau, NIDA research monograph 60 (1985) 17-24.

[10] G.D. Anderson, Clinical pharmacokinetics 44 (2005) 989-1008.

[11] H. Malm, J. Martikainen, T. Klaukka, P.J. Neuvonen, Drug safety 27 (2004) 899-908.

[12] R. Sannerstedt, P. Lundborg, B.R. Danielsson, I. Kihlstrom, G. Alvan, B. Prame, E. Ridley, Drug safety 14 (1996) 69-77.

[13] G.G. Briggs, R.K. Freeman, S.J. Yaffe, Drugs in pregnancy and lactation: a reference guide to fetal and neonatal risk, Lippincott Williams \& Wilkins2012.

[14] P. Baranczewski, A. Stanczak, K. Sundberg, R. Svensson, A. Wallin, J. Jansson, P. Garberg, H. Postlind, Pharmacological reports : PR 58 (2006) 453-472.

[15] R. Gebhardt, J.G. Hengstler, D. Muller, R. Glockner, P. Buenning, B. Laube, E. Schmelzer, M. Ullrich, D. Utesch, N. Hewitt, M. Ringel, B.R. Hilz, A. Bader, A. Langsch, T. Koose, H.J. Burger, J. Maas, F. Oesch, Drug metabolism reviews 35 (2003) 145-213.

[16] R. Yuan, S. Madani, X.X. Wei, K. Reynolds, S.M. Huang, Drug metabolism and disposition: the biological fate of chemicals 30 (2002) 1311-1319.

[17] C.M. Habibullah, I.H. Syed, A. Qamar, Z. Taher-Uz, Transplantation 58 (1994) 951-952.

[18] M.N. Rao, B. Biju, A.K. Ansar, S. Mujeeb, M. Ramesh, N.R. Srinivas, Xenobiotica; the fate of foreign compounds in biological systems 33 (2003) 1233-1245.

[19] H.M. Jones, J.B. Houston, Drug metabolism and disposition: the biological fate of chemicals 32 (2004) 973-982.

[20] A.P. Li, Drug discovery today 6 (2001) 357-366.

[21] K. Hoshino, H. Inouye, T. Unokuchi, M. Ito, N. Tamaoki, K. Tsuji, Diabete \& metabolisme 2 (1976) 157-158.

[22] U. Yasar, E. Eliasson, C. Forslund-Bergengren, G. Tybring, M. Gadd, F. Sjoqvist, M.L. Dahl, European journal of clinical pharmacology 57 (2001) 729-735. 
[23] S.M. de Morais, G.R. Wilkinson, J. Blaisdell, K. Nakamura, U.A. Meyer, J.A. Goldstein, The Journal of biological chemistry 269 (1994) 15419-15422.

[24] N.L. Kerry, A.A. Somogyi, F. Bochner, G. Mikus, British journal of clinical pharmacology 38 (1994) 243-248.

[25] K.C. Patki, L.L. Von Moltke, D.J. Greenblatt, Drug metabolism and disposition: the biological fate of chemicals 31 (2003) 938-944.

[26] U. Food and Drug Administration, Guidance for Industry Drug Interaction Studies - Study Design, Data Analysis, and Implications for Dosing and Labeling http://www.fda.gov/OHRMS/DOCKETS/98fr/06d-0344-gdl0001.pdf, 2006.

[27] R.S. Obach, A.E. Reed-Hagen, Drug metabolism and disposition: the biological fate of chemicals 30 (2002) 831-837.

[28] H.S. Brown, M. Griffin, J.B. Houston, Drug metabolism and disposition: the biological fate of chemicals 35 (2007) 293-301.

[29] M.A. Mohutsky, J.Y. Chien, B.J. Ring, S.A. Wrighton, Pharmaceutical research 23 (2006) 654-662.

[30] R.S. Obach, Drug metabolism and disposition: the biological fate of chemicals 27 (1999) 1350-1359.

[31] Y. Naritomi, S. Terashita, A. Kagayama, Y. Sugiyama, Drug metabolism and disposition: the biological fate of chemicals 31 (2003) 580-588.

[32] K.P. Kanebratt, T.B. Andersson, Drug metabolism and disposition: the biological fate of chemicals 36 (2008) 1444-1452.

C 2016 by the authors; licensee IAPC, Zagreb, Croatia. This article is an open-access article distributed under the terms and conditions of the Creative Commons Attribution license (http://creativecommons.org/licenses/by/3.0/) (cc) EY 